\title{
What is a profession?
}

\author{
J. W. Aukett ${ }^{1}$
}

\section{In brief}

Defending the status of dentistry as a profession is fundamental to maintaining an appropriate relationship with all stakeholders.
Arguments suggesting that dentistry is no longer a profession due the loss of autonomy may be valid, but only in the context of an out-of-date definition of what is a profession.
Arguments are proposed that the changing nature of society and of health and disease now require a more modern and realistic definition of what is a profession.

Loss of autonomy should mean that dentistry may no longer be viewed as a profession. Relationships between medical professions, patients and politicians evolve as society disease patterns change. A new and more appropriately modern definition of what constitutes a profession may now be needed.

Stephen Hancocks argues that dentistry is no longer a profession because, among other issues, we have lost one of the key definitions, that of autonomy. ${ }^{1}$ A similar view has recently been echoed by Holden. ${ }^{2}$ Not only have we lost our collective professional autonomy by the constitution of the General Dental Council being a majority of lay people, but it appears that we have lost also our individual autonomy to manage our dentist/patient relationship. Guidance and standards issued by bodies such as FDGP, and British endodontic and periodontal societies are now seen by the CQC as defined and invariable pathways of treatment planning and execution. Failure to follow prescribed guidance is seen as failing to conform to the 'Are services effective?' question. Failing to conform to fundamental standards is an offence under the Health and Social Care Act 2008 (Regulated Activities) Regulations 2014.

This in itself does not mean that dentistry is not a profession. Autonomy is only one feature of a number of characteristics that define a profession. Ronald Pavalko's OccupationalProfessional model ${ }^{3}$ lists seven other dimensions as well as autonomy, including intellectual technique, relevance to social

${ }^{1}$ Retired General Dental Practitioner, University Lecturer, Compliance Consultant

Correspondence to: J. W. Aukett

Email: j.aukett@sky.com

Refereed Paper. Accepted 12 June 2017

DOI: $10.1038 /$ sj.bdj.2017.754 values, complexity of training, motivation, commitment, and ethical values. Lord Benson speaking in a debate in the House of Lords in 1992 offered a list of five distinguishing characteristics which separate a profession from 'just another job. ${ }^{4}$ These include:

- Rules and standards over and above norms required by law

- A membership which is independent in thought and outlook but which subordinates its private interests in favour of support for the governing body

- Disciplinary action if standards are not practised

- Leadership.

Under an evolving and developing society, the real question now is 'What makes a profession in the twenty-first century?' The definition of what is a profession needs to be reassessed. Since McKeown $^{5}$ and Illich ${ }^{6}$ published their apparent criticism of the dominance of the medical professions and the medical model of health and disease, others have sought to re-define the roles, responsibilities, and accountability of medicine and other 'professions'. Paul Morrell ${ }^{4}$ describes 50 years of gradual but relentless change, sweeping professions from their pedestal, and climaxing in the Thatcher government's attack on any closed shop situation.

In our medical world, there are at least five areas of change that have challenged and will continue to challenge the traditional definition of profession:
1. One of the most influential changes lies in the changing face of morbidity and mortality. From the rampant infectious diseases of earlier centuries, the majority of causes of ill health (including dental caries, periodontal disease and most oral cancers) are classified as chronic non-communicable diseases. Our understanding of these conditions is that the main determinant of health is lifestyle, not pathological entities, and so the treatment and prevention lies with social and behavioural factors rather than medical or surgical interventions, ie our traditional professional expertise. It has been argued that many clinicians make the mistake of believing they can know which treatment choices are best for patients, even though the choices depend heavily on the beliefs, values, and circumstances of the patient, variables about which the physician has little knowledge ${ }^{7}$

2. The rampant spread of the Internet and its accessibility to everyone has both advantages and disadvantages. People are now much better informed and educated and can access information and arguments, both valid and speculative. Expectations are higher. Enfranchisement is a universal feature enabling individual rights to take priority and professional opinions to be challenged. Coupled with this element is the debate over whether 'informed' consent is a reality. The role of the patient in controlling their own lives redefines the meaning of autonomy in a professional context 
3. The move towards large practices and chains removes much of the independence (autonomy) and entrepreneurialism of a clinician. Common policies and standards for audit require standard responses to care requirements rather than dealing with each situation as a unique relationship between the physician, the patient and the context. Ownership of practices by nondental directors adds to the confusion of the ownership of relationships and interactions between physician and patient

4. Holden ${ }^{2}$ reports arguments that the transition of dental care from mainly curative to the pursuit of cosmetic interventions challenges the social contract, the basic relationship between society and professions

5. Changes in acceptable ethical values from the ancient and ultra-traditional Hippocratic Oath and Prayer of Maimonides have been inevitable. Veatch ${ }^{7}$ graphically describes the conflict between these earlier codes and those of secular and religious groups, development of the AMA Principles of Medical Ethics, and how the WMA Declaration of Geneva evolved from changes in society. Parallel changes in dental ethics can be seen in the continual evolution of the code of ethics for dentists in the European Union. ${ }^{8}$

Elements of what we believe to be professional values and characteristics run through all arguments, values of altruism, honesty, trustworthiness, and the priority of the needs of patients over all other considerations. The extensive body of knowledge and training is characterised not only by facts and predetermined action/reaction pathways, but by the skilled and appropriate application of that knowledge to the personal and social context of the patient and society. Autonomy perhaps needs defining not from the perspective of the physician, but in the context of respect for the autonomy of the patient, their rights, their responsibilities, and also those of society as a cohesive entity. Ideals may not have changed drastically, but interpreting them now in the current contexts may be the basis of a more realistic definition of professionalism befitting the twenty-first century.

So the question should not be 'Are we a profession?', but 'what is a profession in the twenty-first century'? Then we can ask if the practice of dentistry is a profession.

1. Hancocks S. Professionalism in spite of all (Editorial). $\mathrm{Br}$ Dent J 2017; 222: 561.

2. Holden A C. Self-regulation in dentistry and the social contract. Br Dent J 2016; 221: 449-451.

3. Pavalko R M. Sociology of occupations and professions. \|linois: Peacock, 1971.

4. Morrell P. Why the professions are being pulled from their pedestal. Management Today February 2016; 42-46.

5. McKeown T. The role of medicine: Dream, mirage or nemesis. Oxford: Blackwell, 1979.

6. Illich I. Medical nemesis: The expropriation of health. 2nd edn. London: Marion Boyar, 1995.

7. Veatch R. Ethical aspects of recommending lifestyle interventions to patients. JAMA 2003: 200: 2660.

8. Council of European Dentists. Code of ethics for dentists in the European Union. CED-DOC-2017-016-FIN-E. 2017. 